\title{
SOCS3 and SOCS6 are required for the risperidone-mediated inhibition of insulin and leptin signaling in neuroblastoma cells
}

\author{
LONGZHEN PIAO $^{1,2^{*}}$, JISOO PARK $^{1 *}$, YUWEN LI $^{1,3}$, SANGHEE SHIN ${ }^{1}$, \\ SOYEON SHIN ${ }^{1}$, GYEYEONG KONG ${ }^{1}$, ROBIN SHRESTHA ${ }^{1}$, \\ QUANGDON TRAN $^{1}$, GANG MIN HUR ${ }^{1}$, JEONG-LAN KIM ${ }^{4}$ and JONGSUN PARK ${ }^{1}$
}

\begin{abstract}
${ }^{1}$ Department of Pharmacology, Metabolic Diseases and Cell Signaling Laboratory, Research Institute for Medical Sciences, College of Medicine, Chungnam National University, Daejeon 301-747, Republic of Korea; ${ }^{2}$ Department of Oncology, Affiliated Hospital of Yanbian University, Yanji, Jilin 133000; ${ }^{3}$ Department of Pharmacy, Xijing Hospital, Fourth Military Medical University, Xi'an, Shaanxi 710032, P.R. China; ${ }^{4}$ Department of Psychiatry, College of Medicine, Chungnam National University, Daejeon 301-131, Republic of Korea
\end{abstract}

Received November 21, 2013; Accepted March 6, 2014

DOI: $10.3892 /$ ijmm.2014.1693

\begin{abstract}
Antipsychotic drugs are regularly used for the treatment of many types of psychiatric disorders. The administration of second-generation antipsychotics is often associated with weight gain and the development of diabetes mellitus; however, the molecular mechanisms underlying the effects of these drugs remain poorly understood. Leptin and insulin play key roles in the regulation of energy balance and glucose homeostasis, and resistance to the actions of these hormones can occur with obesity and inflammation, resulting in the pathogenesis of obesity and type 2 diabetes. In this study, the effects of risperidone on the insulin-induced protein kinase $B$ (PKB) phosphorylation and leptin-stimulated signal transducer and activator of transcription 3 (STAT3) phosphorylation were investigated in the human SH-SY5Y neuroblastoma cell line. The treatment of these cells with risperidone induced the activation of extracellular signal-related kinase (ERK) by cellular cyclic adenosine 3-monophosphate (cAMP)-dependent protein kinase (also known as protein kinase A; PKA) and the mecha-
\end{abstract}

Correspondence to: Dr Jongsun Park, Department of Pharmacology, Metabolic Diseases and Cell Signaling Laboratory, Research Institute for Medical Sciences, College of Medicine, Chungnam National University, 6 Munhwa-dong, Jung-gu, Daejeon 301-747, Republic of Korea

E-mail: insulin@cnu.ac.kr

Dr Jeong-Lan Kim, Department of Psychiatry, College of Medicine, Chungnam National University, 6 Munhwa-dong, Jung-gu, Daejeon 301-747, Republic of Korea

E-mail:kimjl@cnu.ac.kr

*Contributed equally

Key words: risperidone, antipsychotic drug, insulin, leptin, protein kinase B, suppressor of cytokine signaling nisms involved include the induction of suppressor of cytokine signaling 3 (SOCS3) and suppressor of cytokine signaling 6 (SOCS6) expression. The risperidone-induced ERK activation induced an upregulation of SOCS3 and SOCS6 mRNA expression levels. Taken together, these results suggest that risperidone modulates SOCS3 and SOCS6 expression through adenylate cyclase-mediated ERK activation, which, in turn, leads to an inhibition of insulin-induced PKB phosphorylation and leptinstimulated STAT3 phosphorylation. Eventually, these effects result in excessive body weight gain due to the inhibition of both the leptin and insulin signaling pathways.

\section{Introduction}

Treatment with second-generation (atypical) antipsychotics has been associated with weight gain and the development of diabetes mellitus (1). Although atypical antipsychotic drugs are of great benefit to a wide variety of individuals with psychiatric disorders, particularly patients with schizophrenia (2), clinical observations indicate that these drugs can cause adverse metabolic effects (3), including an increased risk of obesity, diabetes and metabolic syndrome (4). However, the mechanisms underlying this process remain unclear. Dopamine D2 receptors are of key interest to the pathophysiology of schizophrenia (5), as all antipsychotics, typical as well as atypical, appear to be dopamine D2 receptor antagonists (6), particularly for postsynaptic receptors (7). Risperidone therapy is associated with modest weight gain (8). Claus et al (9) reported a mean weight gain of $2 \mathrm{~kg}$ after 12 weeks of treatment with risperidone with a mean final dose of $12 \mathrm{mg}$ /day; similar gains were reported in the study by Owens (10).

Body weight is determined by the balance between energy intake and expenditure. Leptin and insulin are key hormones in the regulation of energy balance and glucose homeostasis $(11,12)$. The actions of insulin are mediated through the insulin receptor (IR), which belongs to the tyrosine kinase receptor family. The binding of insulin to its receptor leads 
to a rapid autophosphorylation of the receptor followed by the tyrosine phosphorylation of IR substrate (IRS) proteins, which induce the activation of downstream signaling cascades, including phosphatidylinositol-3 kinase (PI3K) and protein kinase B/Akt (PKB/Akt) (13). Leptin is a major signaling molecule from the periphery that acts in the hypothalamus to regulate energy homeostasis and body adiposity $(14,15)$. The effects of leptin involve the long isoform of the leptin receptor in the hypothalamus (16), where it influences pro-opiomelanocortin (POMC) neurons, which activate the secretion of an anorexic neuropeptide ( $\alpha$-melanocyte-stimulating hormone), and neuropeptide Y/agouti gene-related protein (NPY/AGRP) neurons, which inhibit the expression of an orexic neuropeptide (NPY). Leptin receptors belong to the cytokine receptor superfamily. The binding of leptin to its receptor activates Janus kinase 2 (JAK2), which, in turn, phosphorylates tyrosine residues in receptor tails, leading to the recruitment and activation of signaling molecules $(16,17)$. Among these signaling molecules, signal transducer and activator of transcription 3 (STAT3) directly transmits the signals to the nucleus (18). The suppressor of cytokine signaling (SOCS) family of proteins was first discovered in 1997 (19) and is also referred to as JAK-binding proteins, signal transducer and activation of transcription (STAT)-induced STAT inhibitors, or cytokineinducible Src homology-containing proteins family (20). SOCS proteins appear to be inducible negative regulators of cytokine signaling through the inhibition of the JAK/STAT pathway (20).

A key feature of human insulin and leptin resistance involves a defect in the ability of insulin to stimulate PKB phosphorylation and leptin-induced STAT3 phosphorylation. Thus, in this study, we investigated whether risperidone exerts direct biological effects on the insulin-induced PKB activation and leptin-stimulated STAT3 phosphorylation in cultured SH-SY5Y cells. Our results demonstrated that risperidone reduced both insulin-mediated PKB activation and leptininduced STAT3 phosphorylation. Furthermore, risperidone significantly increased the mRNA levels of SOCS3 and SOCS6 in an extracellular signal-related kinase (ERK)1/2-dependent manner. Taken together, these results clearly indicate that the actions of risperidone are mediated through the induction of SOCS3 and SOCS6 expression, which, in turn, inhibit insulininduced PKB phosphorylation. Moreover, the induction of SOCS3 expression leads to a modulation of leptin-stimulated STAT3 phosphorylation; this results in the inhibition of the leptin and insulin signaling pathways. These effects of risperidone may be responsible for the antipsychotic drug-induced weight gain observed in patients with psychiatric disorders.

\section{Materials and methods}

Antibodies and reagents. The following antibodies were used: anti-PKB, anti-p-PKB (Ser473), anti-STAT3, antip-STAT3 (Tyr705), anti-ERK1/2 and anti-p-ERK1/2 antibodies were purchased from Cell Signaling Technology (Danvers, MA, USA). Risperidone was obtained as a gift from Johnson \& Johnson (New Brunswick, NJ, USA). Insulin and forskolin were from Sigma-Aldrich (St. Louis, MO, USA. Recombinant human leptin was purchased from R\&D Systems (Minneapolis, MN, USA). The MEK inhibitor, U0126, and the cellular cyclic adenosine 3-monophosphate (cAMP)-dependent protein kinase (also known as protein kinase A; PKA) inhibitor, H89, were obtained from Calbiochem (La Jolla, CA, USA).

Cell culture. The human SH-SY5Y neuroblastoma cells line were used for all the experiments. The cells were maintained at $37^{\circ} \mathrm{C}, 5 \% \mathrm{CO}_{2}$ in Dulbecco's modified Eagle's medium (DMEM), supplemented with $10 \%$ fetal bovine serum (FBS), $100 \mathrm{U} / \mathrm{ml}$ penicillin and $100 \mathrm{~g} / \mathrm{ml}$ streptomycin. For the treatment of the SH-SYSY cells with risperidone and forskolin, the cells were starved for $24 \mathrm{~h}$ followed by treatment of the cells with $100 \mathrm{nM}$ risperidone or $10 \mu \mathrm{M}$ forskolin for the indicated periods of time $(0,2,6$, and $12 \mathrm{~h})$. The control sample was the untreated cells.

Western blot analysis. After the treatment of the cells with the different reagents as described in the figure legends, the cells were washed twice in ice-cold PBS and lysed at $4^{\circ} \mathrm{C}$ in the lysis buffer, containing $50 \mathrm{mM}$ Tris- $\mathrm{HCl}(\mathrm{pH} 7.5), 25 \mathrm{mM} \mathrm{NaF}$, $40 \mathrm{mM} \beta$-glycerol phosphate ( $\mathrm{pH} 7.5$ ), $120 \mathrm{mM} \mathrm{NaCl}$ and $1 \%$ NP-40, $0.1 \mathrm{mM}$ phenylmethylsulfonyl fluoride, $0.1 \mathrm{mM}$ sodium vanadate and $1 \mathrm{mM}$ benzamidine. The protein concentration of the samples was determined by the Bradford protein assay with bovine serum albumin as a standard. The cell lysates were analyzed by $10 \%$ SDS-polyacrylamide gel electrophoresis and blotted onto polyvinylidene difluoride membranes. After blocking with 5\% skim milk in Tris-buffered saline (TBS) containing $0.02 \%$ Tween-20, the membranes were probed with the corresponding antibodies and visualized by enhanced chemiluminescence, according to the manufacturer's instructions (GE Healthcare, Pittsburgh, PA, USA).

Reverse transcription (RT)-PCR. Total cellular RNA was isolated from the SH-SY5Y cells using PureHelix RNA Extraction Solution (NanoHelix Co., Ltd., Boston, MA, USA) following the manufacturer's instructions. cDNA was synthesized from $2 \mu \mathrm{g}$ of RNA using oligo(dT) primer and a first-strand cDNA synthesis kit (Promega, Madison, WI, USA). The housekeeping gene, glyceraldehyde-3-phosphate dehydrogenase (GAPDH), was amplified as a control for RNA loading and variations in cDNA synthesis efficiency. The following primer sets were designed for the amplification of human SOCS1, SOCS3, SOCS6 and SOCS7. The following primers were used: SOCS1 Forward, CAC GCA CTT CCG CAC ATT and reverse, AGC AGC TCG AGG AGG CAG; SOCS3 forward, GAG TAC CAC CTG AGT CTC CA and reverse, GAC CTC TCT CTC TTC CAC CT; SOCS6, forward, AAA TGT CCT TTT CTC CGG TC and reverse, AAT TCA TTG GCC CCC AAT AC; and SOCS7, forward, GCG GAA TTC ATG GGT GAT GTT and reverse, TAT GGA TCC GC CTC ATT AGT AGC.

Statistical analysis. The quantification of the western blot analysis results was carried out using the Tina version 2.1 program (Raytest Isotopenmegerate). Briefly, the relative intensity (area density) of the bands of interest was quantified using a densitometer. The background value from a blank band was subtracted. The results were calculated as the ratio change compared with the corresponding control bands. Data are presented as the means \pm SD of the 3 independent experiments. The results were analyzed using the Student's t-test (SPSS version 12.0 software, SPSS Inc., Chicago, IL, USA). A value 
A

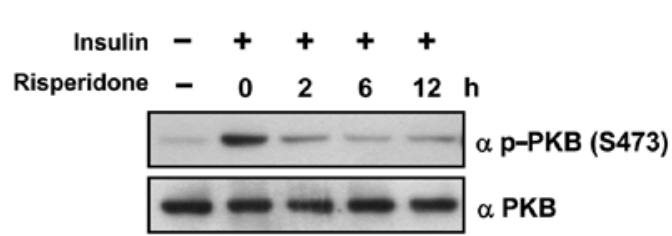

B

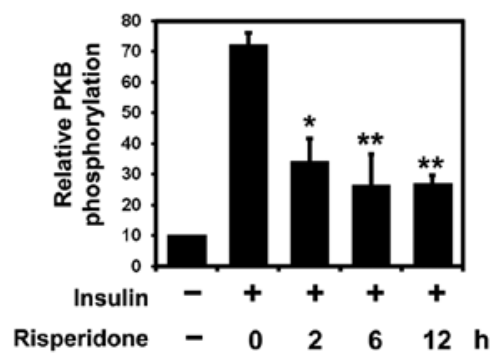

Figure 1. Effects of risperidone on insulin-mediated protein kinase $\mathrm{B}$ (PKB) activation in SH-SY5Y cells. (A) SH-SY5Y cells were serum-starved for $24 \mathrm{~h}$ and pre-treated with $100 \mathrm{nM}$ risperidone for the indicated periods of time followed by $100 \mathrm{nM}$ insulin stimulation for $15 \mathrm{~min}$. Cells were harvested and analyzed by western blotting with anti-phospho-Ser473 (S473) PKB antibody or anti-PKB antibody. (B) Relative density was obtained by densitometry of the corresponding immunoblot data. Statistical differences of PKB phosphorylation were determined by normalizing values for total PKB at each lane. The results are the means \pm standard deviation (SD) of 3 independent experiments. ${ }^{*} \mathrm{p}<0.05 ;{ }^{* *} \mathrm{p}<0.01 . \alpha$ indicates antibody.

of $\mathrm{p}<0.05$ was considered to indicate a statistically significant difference, and $\mathrm{p}<0.01$ a highly significant difference compared with the corresponding control values.

\section{Results}

Risperidone inhibits insulin-mediated PKB activity in SH-SY5Y cells. Risperidone is an antipsychotic drug widely used to treat patients with schizophrenia (21). Treatment with risperidone often leads to an increase in body weight; however, the underlying mechanisms remain unelucidated. Therefore, in this study, the effects of risperidone on insulin signaling were investigated. Western blot analyses utilizing an anti-phosphoPKB antibody revealed that PKB phosphorylation on Ser473 was markedly inhibited in the SH-SY5Y cells following treatment with risperidone, beginning at $2 \mathrm{~h}$ post-treatment and continuing until $12 \mathrm{~h}$ post-treatment (Fig. 1A). Statistical analyses of the 3 independent experiments clearly indicated that insulin-mediated PKB activation was inhibited by risperidone in the SH-SY5Y cells (Fig. 1B).

Leptin-mediated STAT3 activation is blocked by risperidone in SH-SY5Y cells. The adipocyte-derived hormone, leptin, acts as a satiety signal in hypothalamic nuclei and regulates energy homeostasis and body weight $(22,23)$. To evaluate the influence of risperidone on the leptin signaling pathway, the SH-SY5Y cells were pre-treated with $100 \mathrm{nM}$ risperidone for the indicated periods of time, followed by treatment with leptin for $30 \mathrm{~min}$. The leptin-induced STAT3 phosphorylation at Tyr705 was markedly inhibited by risperidone, beginning at $2 \mathrm{~h}$ post-treatment and continuing to $12 \mathrm{~h}$ post-treatment (Fig. 2A and B). This indicates that risperidone inhibits the insulin and leptin signaling pathways and may be an important
A

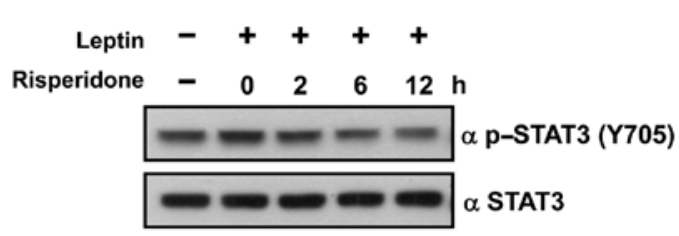

B

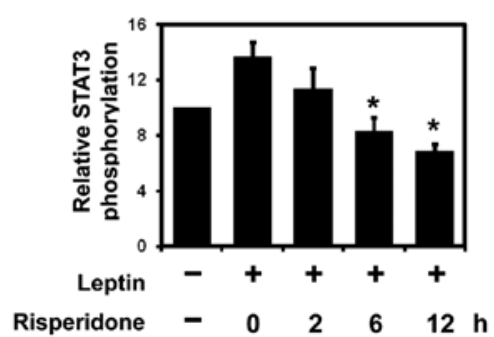

Figure 2. Changes in leptin-stimulated phosphorylation of signal transducer and activator of transcription 3 (STAT3) by risperidone in SH-SY5Y cells. (A) SH-SY5Y cells were serum-deprived for $24 \mathrm{~h}$ and pre-treated with $100 \mathrm{nM}$ risperidone for the indicated periods of times followed by $100 \mathrm{nM}$ leptin stimulation for $30 \mathrm{~min}$. Cells were harvested and analyzed by western blotting with anti-phospho-STAT3 (Tyr705; Y705) antibody or anti-STAT3 antibody. (B) Relative density was obtained by densitometry of the corresponding immunoblot data. Statistical differences of STAT3 phosphorylation were determined by normalizing values for total STAT3 at each lane. The results are the means \pm SD of 3 independent experiments. " $\mathrm{p}<0.05 ;{ }^{* *} \mathrm{p}<0.01$. $\alpha$ indicates antibody.

mechanism underlying body weight gain in schizophrenic patients following treatment with risperidone.

Adenylate cyclase activity is required for the inhibition of $P K B$ and STAT3 phosphorylation in SH-SY5Y cells. Atypical antipsychotic drugs, including risperidone, primarily antagonize dopamine D2 receptors, resulting in an elevation of cellular cyclic adenosine 3-monophosphate (cAMP) (24). To further evaluate the effects of risperidone on insulin/leptin signaling, forskolin, an activator of adenylate cyclase (25), was utilized. The SH-SY5Y cells were pre-treated with $10 \mu \mathrm{M}$ forskolin for the indicated periods of time, followed by either insulin or leptin stimulation. Western blot analyses with phosphospecific antibodies demonstrated that the hormone-mediated phosphorylation of PKB and STAT3 was blocked by pretreatment with forskolin at $2 \mathrm{~h}$, after which it recovered slowly (Fig. 3A and B). This suggests that the forskolin-mediated inhibition of PKB and STAT3 phosphorylation is regulated by adenylate cyclase.

Upregulation of SOCS3 and SOC6 mRNA levels following treatment with risperidone and forskolin in $\mathrm{SH}$-SY5Y cells. The elevation of intracellular cAMP-induced SOCS3 expression and the inhibition of STAT3 phosphorylation on the tyrosine residue in endothelial cells have been described previously (26). Furthermore, SOCS3 and other SOCS proteins (SOCS1, SOCS6 and SOCS7) appear to modulate insulinmediated PKB signaling by several mechanisms (27-30). Thus, in this study, the mRNA levels of SOCS proteins were examined in the SH-SY5Y cells. Following the administration of risperidone to the cells, the mRNA levels of SOCS3 and SOCS6, but not those of SOCS1 and SOCS7, gradually increased in time-dependent manner (Fig. 4A). To further 
A
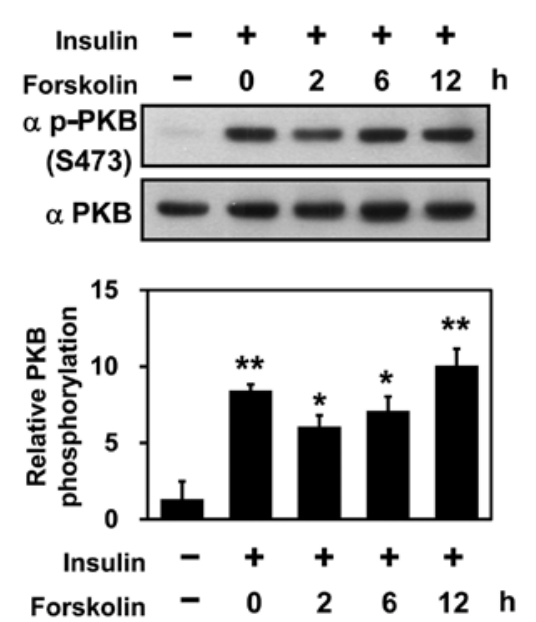

B
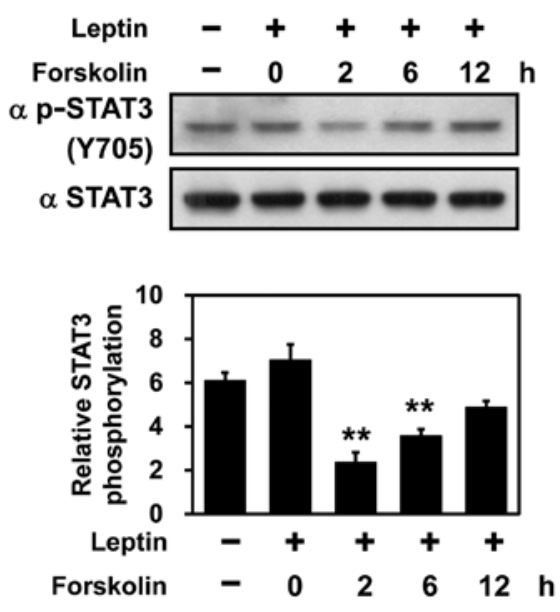

Figure 3. Effects of forskolin on protein kinase B (PKB) activation and signal transducer and activator of transcription 3 (STAT3) phosphorylation in SH-SY5Y cells. (A) SH-SY5Y cells were serum-starved for $24 \mathrm{~h}$ and pre-treated with $10 \mu \mathrm{M}$ forskolin for indicated periods of time followed by $100 \mathrm{nM}$ insulin stimulation for 15 min. Total cell lysates were analyzed by immunoblotting using anti-phospho Ser473 (S473) PKB antibody and anti-PKB antibody (top panel). Relative density was obtained by densitometry of the corresponding immunoblot data. Statistical differences of PKB phosphorylation were determined by normalizing values for total PKB at each lane (bottom panel). (B) Cells were pre-treated with $10 \mu \mathrm{M}$ forskolin for the indicated periods of time followed by treatment of cell with $100 \mathrm{nM}$ leptin for $30 \mathrm{~min}$ and monitored by western blot analysis with anti-phospho Tyr705 (Y705) STAT3 antibody or anti STAT3 antibody (top panel). Relative density was obtained by densitometry of the corresponding immunoblot data. Statistical differences of STAT3 phosphorylation were determined by normalizing values for total STAT3 at each lane (bottom panel). The results are the means \pm SD of 3 independent experiments. ${ }^{*} \mathrm{p}<0.05 ;^{* *} \mathrm{p}<0.01$. $\alpha$ indicates antibody.

A

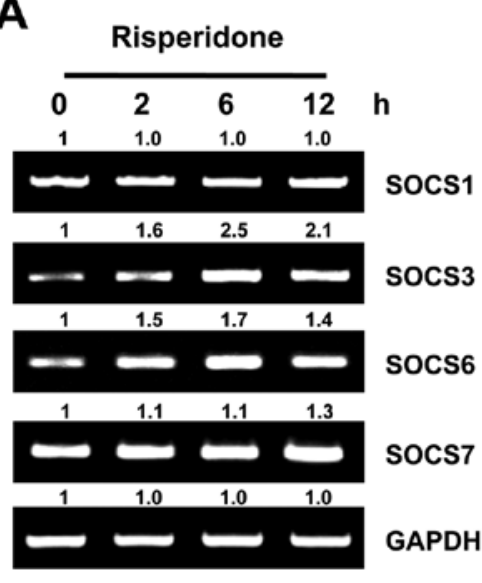

B

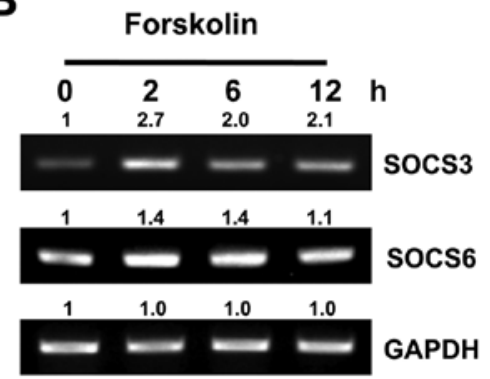

Figure 4. Effects of risperidone on mRNA levels of suppressor of cytokine signaling (SOCS)3 and SOCS6. (A) SH-SY5Y cells were serum-starved for 24 h and treated with $100 \mathrm{nM}$ risperidone for the indicated periods of time. Total RNA was prepared and subjected to the reverse transcription. The resulting cDNA was used to perform RT-PCR with SOCS1, SOCS3, SOCS6 and SOCS7 specific primers. The quantification of the PCR products is shown as a fold induction compared to the control. (B) SH-SY5Y cells were serum-starved for $24 \mathrm{~h}$ and exposed with $10 \mu \mathrm{M}$ forskolin for the indicated periods of time. Following the extraction of total RNA, RT-PCR were performed for SOCS3 and SOCS6. The quantification of the PCR products is shown as a fold induction compared to the control.

confirm that this action is dependent on adenylate cyclase activity, the cells were treated with forskolin. The expression of SOCS3 and SOCS6 was elevated at $2 \mathrm{~h}$ post-treatment and gradually decreased thereafter (Fig. 4B). This indicates that the risperidone-mediated induction of SOCS3 and SOCS6 is modulated by adenylate cyclase.

Risperidone-mediated ERK phosphorylation is dependent on PKA activity. cAMP and PKA are evolutionary conserved molecules with a well-established position in the complex network of signal transduction pathways (31). Intracellular cAMP can activate the mitogen-activated protein kinase
(MAPK)/ERK cascade through either Ras or Rap1 activation in several cell types (32). Therefore, the effects of either risperidone or forskolin on ERK1/2 activity in the SH-SY5Y cells were monitored. Western blot analyses with phosphospecific anti-ERK antibodies revealed that ERK1/2 activation occurred in the risperidone- or forskolin-treated cells (Fig. 5A), suggesting that adenylate cyclase activity is important for risperidone-mediated ERK1/2 activation. To further determine the possible involvement of PKA in these events, H89, a specific PKA inhibitor, was utilized. Risperidone- or forskolinmediated ERK1/2 activation was completely blocked in the SH-SY5Y cells treated with H89 (Fig. 5B), indicating that 
A
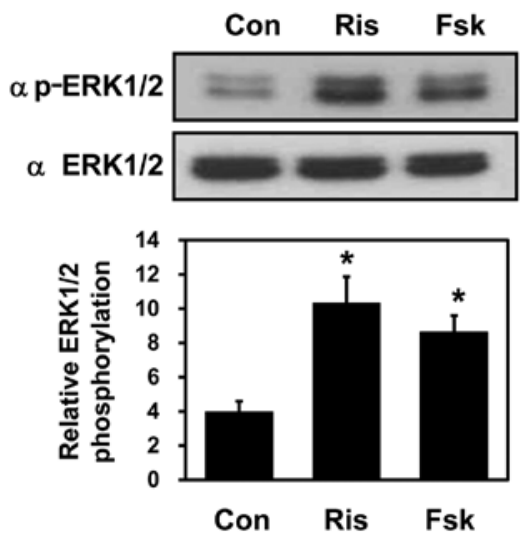

B
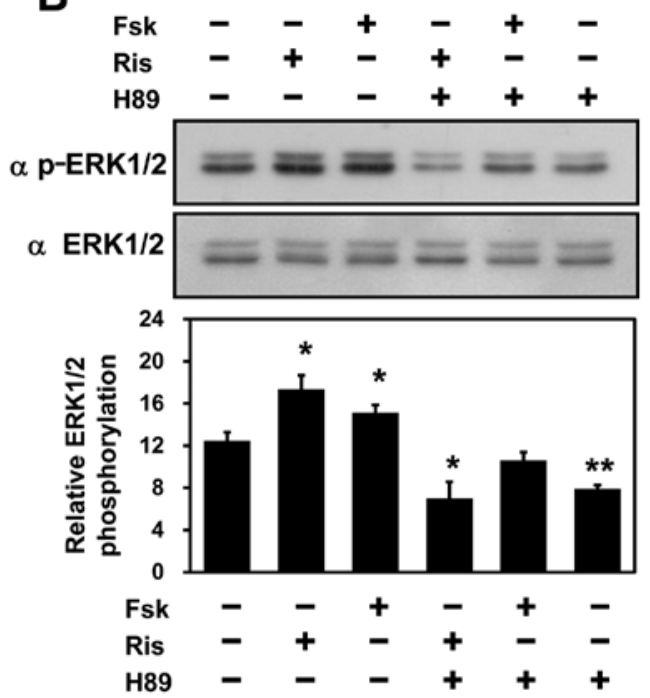

Figure 5. Protein kinase (PKA) activity is required for the activation of extracellular signal-related kinase 1/2 (ERK1/2) by risperidone. (A) SH-SY5Y cells were treated with $100 \mathrm{nM}$ risperidone and $10 \mu \mathrm{M}$ forskolin for $6 \mathrm{~h}$. Cells were harvested and analyzed by western blotting with phospho-ERK1/2 antibody and total ERK1/2 antibody (top panel). Relative density was obtained by densitometry of the corresponding immunoblot data. Statistical differences of ERK1/2 phosphorylation were determined by normalizing values for total ERK1/2 at each lane (bottom panel). (B) SH-SY5Y cells were serum-starved for $24 \mathrm{~h}$ and pre-treated with $5 \mu \mathrm{M} \mathrm{H} 89$ (PKA inhibitor) and DMSO for $30 \mathrm{~min}$, followed by treatment of the cells with either $100 \mathrm{nM}$ risperidone (Ris) or $10 \mu \mathrm{M}$ forskolin (Fsk) for $6 \mathrm{~h}$. Samples were analyzed by western blotting with phospho-ERK1/2 antibody and total ERK1/2 antibody (top panel). Relative density was obtained by densitometry of the corresponding immunoblot data. Statistical differences of ERK1/2 phosphorylation were determined by normalizing values for total ERK1/2 at each lane (bottom panel). The results are the mean \pm SD of 3 independent experiments. ${ }^{*} \mathrm{p}<0.05 ;{ }^{* *} \mathrm{p}<0.01$. Con, control (untreated); Ris, risperidone; Fsk, forskolin. $\alpha$ indicates antibody.

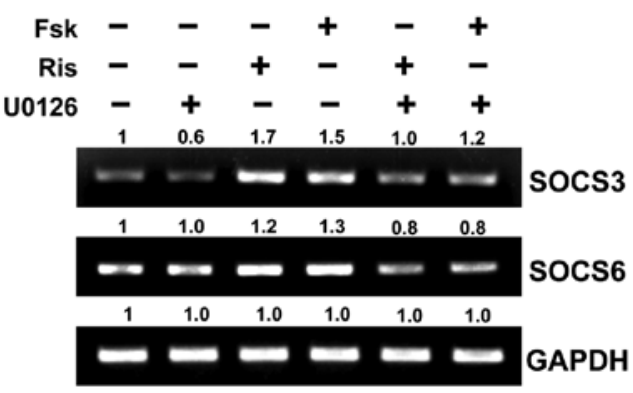

Figure 6. Effects of U0126 on risperidone-induced expression of suppressor of cytokine signaling (SOCS)3 and SOCS6. SH-SY5Y cells were pre-treated with $100 \mathrm{nM}$ U0126 (MEK inhibitor) and DMSO for $30 \mathrm{~min}$ followed by treatment of the cells with $100 \mathrm{nM}$ risperidone) and $10 \mu \mathrm{M}$ forskolin for $6 \mathrm{~h}$. Following the extraction of total RNA, RT-PCR were performed for SOCS3 and SOCS6. The quantification of the PCR products is shown as a foldinduction compared to the control. Ris, risperidone; Fsk, forskolin.

PKA activity is required for risperidone- or forskolin-mediated ERK1/2 activation.

Upregulation of SOCS3 and SOCS6 by treatment with risperidone is blocked by the MEK inhibitor, U0126. Sands et al (26) reported that the elevation of intracellular cAMP promotes the phosphorylation of ERK1/2, which, in turn, leads to the induction of SOCS3 protein levels in vascular endothelial cells. To further investigate the possibility that cAMP-induced MAPK/ERK activation is required for SOCS3 induction, the MEK inhibitor, U0126, was employed. RT-PCR using SOCS3- and SOCS6-specific primers revealed that the risperidone- or forskolin-mediated upregulation of SOCS3 and SOCS6 is dependent on MEK1/2 activity (Fig. 6).

\section{Discussion}

As an important side-effect of antipsychotic medication, weight gain can be a serious health issue in patients with schizophrenia and other psychoses (8) and may have adverse implications with adherence to long-term antipsychotic therapy. Excessive weight gain may also lead to other adverse health effects, including type 2 diabetes, hyperlipidemia and cardiovascular disease (33). Risperidone and olanzapine, two widely used atypical antipsychotics, have similar efficacy in the treatment of patients with schizophrenia $(34,35)$. However, weight gain occurs to varying extents depending on the particular atypical antipsychotic drug $(34,35)$.

Risperidone is associated with modest weight gain that is not related to the dose used. The majority of studies have reported a mean weight gain of approximately $2-2.5 \mathrm{~kg}$ over treatment periods ranging from 8 weeks to 1 year $(9,10,36)$. The action of risperidone is mediated through an inhibition of the post-synaptic dopamine D2 receptors (7). Insulin and leptin are major peripheral signals acting in the hypothalamus to regulate energy homoeostasis and body adiposity (11). IRs and (long isoform) leptin receptors share a number of signaling cascades, such as PI3K/PKB and JAK2/STAT3 $(16,22)$. Studies have demonstrated that atypical antipsychotic drugs exhibit inverse agonist activity at dopamine D2 receptors (37) and stimulate cAMP formation (24). Furthermore, the inhibition of dopamine D2 receptors can activate adenylyl cyclase, increase the levels of cAMP, and activate PKA $(38,39)$ and ERK; in addition, the cAMP response element-binding protein (CREB) can be activated by risperidone in a PKA-dependent manner (40).

To the best of our knowledge, this study provides the first evidence that risperidone regulates both insulin and leptin signaling in the human SH-SY5Y neuroblastoma cell line. 


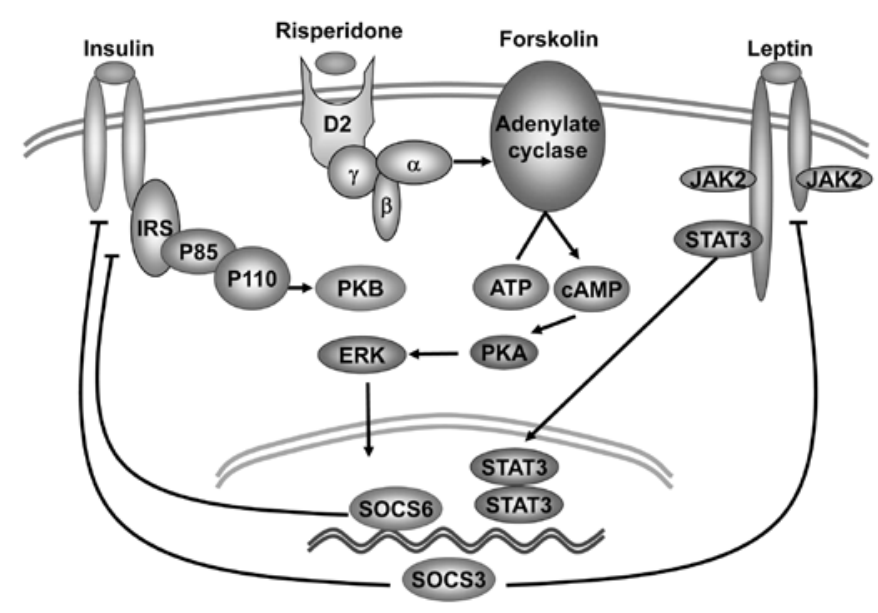

Figure 7. Schematic illustration of the suggested mechanisms of action of risperidone on insulin and leptin signaling pathways. Treatment with risperidone specifically increases intercellular cAMP accumulation, through the inhibition of dopamine D2 receptor. This results in protein kinase A (PKA)-mediated extracellular signal-related kinase (ERK) activation, leading to the induction of suppressor of cytokine signaling (SOCS) 3 and SOCS6. SOCS3 can bind to leptin receptor and downregulate the receptor-mediated activation of JAK2/ STAT3 signaling in leptin signaling cascades. In addition, both SOCS3 and SOCS6 can bind to insulin receptor (IR) and IR substrate (IRS)1/2, resulting in the inhibition of IR autophosphorylation and the degradation of IRS1/2 Therefore, risperidone blocks both leptin and insulin hormone signaling pathways through the accumulation of cAMP, PKA-mediated ERK activation and the induction of SOCS3 and SOCS6 expression, resulting in the inhibition of leptin-stimulated-STAT3 phosphorylation and insulin-induced-PKB activation. These effects may be an important mechanism of action of the risperidone-induced insulin and leptin resistance, finally leading to weight gain in schizophrenic patients.

Treatment of the cells with risperidone markedly inhibited insulin-induced PKB activation, as well as leptin-mediated STAT3 phosphorylation (Figs. 1 and 2). These events appear to occur through adenylate cyclase downstream of the dopamine D2 receptor. It has been reported that forskolin inhibits the interleukin (IL)-6-stimulated phosphorylation of STAT3 in human aortic endothelial cells (26). Similarly, the current findings provide evidence that pre-treatment with forskolin leads to an inhibition of insulin-induced PKB phosphorylation and leptin-stimulated STAT3 phosphorylation at $2 \mathrm{~h}$ posttreatment (Fig. 3A and B). Moreover, the degree of inhibition by forskolin treatment of insulin- and leptin-mediated signaling is less effective than risperidone treatment, suggesting that the activation of adenylate cyclase is part of risperidone-mediated signaling events.

Specific members of the SOCS protein family are thought to play a role in the development of leptin and insulin resistance (41). It has been shown that SOCS3 is important in the development of leptin resistance (42), and that the inhibition of insulin is mediated by several SOCS proteins, including SOCS1, SOCS3, SOCS6 and SOCS7 (27-30). It has been suggested that the elevation of intracellular cAMP induces SOCS3 protein expression, leading to the inhibition of leptin and the IL-6-stumulated phosphorylation of STAT3 in human aortic endothelial cells (26). In this study, we found that cAMPinduced SOCS3 protein expression is mediated by ERK1/2. Another study found that the elevation of intracellular SOCS3 levels block insulin signaling through the ubiquitin-mediated degradation of IRS1 and IRS2 (43). Similarly, in this study,
SOCS3 expression was enhanced by stimulation of the cells with risperidone or forskolin (Fig. 4A and B). SOCS6 expression was elevated, whereas the expression of SOCS1 and SOCS7 was unaltered (Fig. 4A). The SOCS6 protein has been shown to be a key factor in the inhibition of insulin-dependent PKB activation and IR-directed IRS1 phosphorylation (28). cAMP-stimulated ERK signaling occurs through several mechanisms and is a cell type-specific event (32), as cAMP can activate ERK1/2 in either a PKA-dependent or PKA-independent manner (44-46). In the current system using SH-SY5Y cells, the effects of risperidone on ERK1/2 were dependent on PKA activity (Fig. 5B). These results were confirmed by pre-treatment of the cells with the MEK inhibitor, U0126, which clearly indicates that the risperidone-induced SOCS3 and SOCS6 protein expression is dependent on ERK1/2 activity (Fig. 6). Thus, these data provide clear evidence that the action of risperidone may be an important mechanism underlying the attenuation of insulininduced PKB phosphorylation and leptin-stimulated STAT3 phosphorylation.

In conclusion, this study demonstrates that the action of risperidone in the human SH-SY5Y neuroblastoma cell line involves the induction of both SOCS3 and SOCS6 proteins. A possible mechanism underlying risperidone-induced insulin and leptin resistance is suggested (Fig. 7). The administration of risperidone triggers the accumulation of cAMP, which leads to the enhancement of the expression of both SOCS3 and SOCS6 in a PKA/ERK1/2 signaling-dependent manner. SOCS3 and SOCS6 block insulin-stimulated PKB activity and SOCS3 inhibits the leptin-stimulated phosphorylation of STAT3. Based on the present data and previously published findings, it is possible to delineate a tentative model in which risperidone, through the cAMP/PKA/ERK pathway, induces the expression of SOCS3 and SOCS6 proteins. These findings suggest that this may be an important mechanism underlying the risperidone-induced insulin and leptin resistance, which leads to weight gain in schizophrenic patients.

\section{Acknowledgements}

The present study was financially supported by the National Research Foundation of Korea (NRF) grant funded by the Korean Government (MEST) (nos. 2007-0054932, 2012R1A1A2004714 and 2012M3A9B6055302), and by a grant from the Korea Healthcare technology R\&D Project, Ministry for Health, Welfare and Family Affairs, Republic of Korea (HI10C0573).

\section{References}

1. Lett TA, Wallace TJ, Chowdhury NI, Tiwari AK, Kennedy JL and Muller DJ: Pharmacogenetics of antipsychotic-induced weight gain: review and clinical implications. Mol Psychiatry 17: 242-266, 2012.

2. Citrome L, Jaffe A, Levine J and Lindenmayer JP: Dosing of quetiapine in schizophrenia: how clinical practice differs from registration studies. J Clin Psychiatry 66: 1512-1516, 2005.

3. Melkersson KI, Dahl ML and Hulting AL: Guidelines for prevention and treatment of adverse effects of antipsychotic drugs on glucose-insulin homeostasis and lipid metabolism. Psychopharmacology (Berl) 175: 1-6, 2004.

4. Scheen AJ and De Hert MA: Abnormal glucose metabolism in patients treated with antipsychotics. Diabetes Metab 33: 169-175, 2007. 
5. Grace AA: Gating of information flow within the limbic system and the pathophysiology of schizophrenia. Brain Res Brain Res Rev 31: 330-341, 2000.

6. Narendran R, Slifstein M, Guillin O, et al: Dopamine (D2/3) receptor agonist positron emission tomography radiotracer [11C]-(+)-PHNO is a D3 receptor preferring agonist in vivo. Synapse 60: 485-495, 2006.

7. Masi G, Cosenza A, Mucci M and Brovedani P: Open trial of risperidone in 24 young children with pervasive developmental disorders. J Am Acad Child Adolesc Psychiatry 40: 1206-1214, 2001.

8. Nasrallah H: A review of the effect of atypical antipsychotics on weight. Psychoneuroendocrinology 28 (Suppl 1): 83-96, 2003.

9. Claus A, Bollen J, De Cuyper H, et al: Risperidone versus haloperidol in the treatment of chronic schizophrenic inpatients: a multicentre double-blind comparative study. Acta Psychiatr Scand 85: 295-305, 1992.

10. Owens DG: Extrapyramidal side effects and tolerability of risperidone: a review. J Clin Psychiatry 55: 29-35, 1994.

11. Morton GJ: Hypothalamic leptin regulation of energy homeostasis and glucose metabolism. J Physiol 583: 437-443, 2007.

12. Niswender KD, Baskin DG and Schwartz MW: Insulin and its evolving partnership with leptin in the hypothalamic control of energy homeostasis. Trends Endocrinol Metab 15: 362-369, 2004.

13. Hemmings BA and Restuccia DF: PI3K-PKB/Akt pathway. Cold Spring Harb Perspect Biol 4: a011189, 2012.

14. Coppari R and Bjorbaek C: Leptin revisited: its mechanism of action and potential for treating diabetes. Nat Rev Drug Discov 11: 692-708, 2012.

15. Obici S, Feng Z, Morgan K, Stein D, Karkanias G and Rossetti L: Central administration of oleic acid inhibits glucose production and food intake. Diabetes 51: 271-275, 2002.

16. Kloek C, Haq AK, Dunn SL, Lavery HJ, Banks AS and Myers MG Jr: Regulation of Jak kinases by intracellular leptin receptor sequences. J Biol Chem 277: 41547-41555, 2002.

17. Myers MG Jr: Leptin receptor signaling and the regulation of mammalian physiology. Recent Prog Horm Res 59: 287-304, 2004

18. White DW, Kuropatwinski KK, Devos R, Baumann H and Tartaglia LA: Leptin receptor (OB-R) signaling. Cytoplasmic domain mutational analysis and evidence for receptor homooligomerization. J Biol Chem 272: 4065-4071, 1997.

19. Starr R, Willson TA, Viney EM, Murray LJ, Rayner JR, Jenkins BJ, Gonda TJ, Alexander WS, Metcalf D, Nicola NA and Hilton DJ: A family of cytokine-inducible inhibitors of signalling. Nature 387: 917-921, 1997.

20. Yoshimura A, Nishinakamura $H$, Matsumura $Y$ and Hanada $T$ : Negative regulation of cytokine signaling and immune responses by SOCS proteins. Arthritis Res Ther 7: 100-110, 2005

21. Miyamoto S, Duncan GE, Marx CE and Lieberman JA: Treatments for schizophrenia: a critical review of pharmacology and mechanisms of action of antipsychotic drugs. Mol Psychiatry 10: 79-104, 2005.

22. Friedman JM and Halaas JL: Leptin and the regulation of body weight in mammals. Nature 395: 763-770, 1998.

23. Spiegelman BM and Flier JS: Obesity and the regulation of energy balance. Cell 104: 531-543, 2001.

24. Nilsson CL and Eriksson E: Haloperidol increases prolactin release and cyclic AMP formation in vitro: inverse agonism at dopamine D2 receptors? J Neural Transm Gen Sect 92: 213-220, 1993.

25. Insel PA and Ostrom RS: Forskolin as a tool for examining adenylyl cyclase expression, regulation, and $\mathrm{G}$ protein signaling. Cell Mol Neurobiol 23: 305-314, 2003.

26. Sands WA, Woolson HD, Milne GR, Rutherford C and Palmer TM: Exchange protein activated by cyclic AMP (Epac)mediated induction of suppressor of cytokine signaling 3 (SOCS-3) in vascular endothelial cells. Mol Cell Biol 26 : 6333-6346, 2006.
27. Banks AS, Li J, McKeag L, et al: Deletion of SOCS7 leads to enhanced insulin action and enlarged islets of Langerhans. J Clin Invest 115: 2462-2471, 2005.

28. Mooney RA, Senn J, Cameron S, et al: Suppressors of cytokine signaling- 1 and -6 associate with and inhibit the insulin receptor. A potential mechanism for cytokine-mediated insulin resistance. J Biol Chem 276: 25889-25893, 2001.

29. Senn JJ, Klover PJ, Nowak IA, et al: Suppressor of cytokine signaling-3 (SOCS-3), a potential mediator of interleukin-6-dependent insulin resistance in hepatocytes. J Biol Chem 278: 13740-13746, 2003.

30. Ueki K, Kondo T and Kahn CR: Suppressor of cytokine signaling 1 (SOCS-1) and SOCS-3 cause insulin resistance through inhibition of tyrosine phosphorylation of insulin receptor substrate proteins by discrete mechanisms. Mol Cell Biol 24 5434-5446, 2004.

31. Wojtal KA, Hoekstra D and van Ijzendoorn SC: cAMP-dependent protein kinase A and the dynamics of epithelial cell surface domains: moving membranes to keep in shape. Bioessays 30 : 146-155, 2008

32. Stork PJ and Schmitt JM: Crosstalk between cAMP and MAP kinase signaling in the regulation of cell proliferation. Trends Cell Biol 12: 258-266, 2002.

33. Metzger BE, Buchanan TA, Coustan DR, et al: Summary and recommendations of the Fifth International WorkshopConference on Gestational Diabetes Mellitus. Diabetes Care 30 (Suppl 2): S251-S260, 2007.

34. Lieberman JA, Stroup TS, McEvoy JP, et al: Effectiveness of antipsychotic drugs in patients with chronic schizophrenia. N Engl J Med 353: 1209-1223, 2005.

35. Tran PV, Hamilton SH, Kuntz AJ, et al: Double-blind comparison of olanzapine versus risperidone in the treatment of schizophrenia and other psychotic disorders. J Clin Psychopharmacol 17: 407-418, 1997 .

36. Csernansky JG, Miller JP, McKeel D and Morris JC Relationships among cerebrospinal fluid biomarkers in dementia of the Alzheimer type. Alzheimer Dis Assoc Disord 16: 144-149, 2002.

37. Akam E and Strange PG: Inverse agonist properties of atypical antipsychotic drugs. Biochem Pharmacol 67: 2039-2045, 2004.

38. Seeman P, Schwarz J, Chen JF, et al: Psychosis pathways converge via D2high dopamine receptors. Synapse 60: 319-346, 2006.

39. Albert PR, Neve KA, Bunzow JR and Civelli O: Coupling of a cloned rat dopamine-D2 receptor to inhibition of adenylyl cyclase and prolactin secretion. J Biol Chem 265: 2098-2104, 1990.

40. Yang BH, Son H, Kim SH, Nam JH, Choi JH and Lee JS Phosphorylation of ERK and CREB in cultured hippocampal neurons after haloperidol and risperidone administration. Psychiatry Clin Neurosci 58: 262-267, 2004.

41. Howard JK and Flier JS: Attenuation of leptin and insulin signaling by SOCS proteins. Trends Endocrinol Metab 17: 365-371, 2006.

42. Bjorbak C, Lavery HJ, Bates SH, et al: SOCS3 mediates feedback inhibition of the leptin receptor via Tyr985. J Biol Chem 275: 40649-40657, 2000

43. Rui L, Yuan M, Frantz D, Shoelson S and White MF: SOCS-1 and SOCS-3 block insulin signaling by ubiquitin-mediated degradation of IRS1 and IRS2. J Biol Chem 277: 42394-42398, 2002.

44. Laroche-Joubert N, Marsy S, Michelet S, Imbert-Teboul M and Doucet A: Protein kinase A-independent activation of ERK and H,K-ATPase by cAMP in native kidney cells: role of Epac I. J Biol Chem 277: 18598-18604, 2002.

45. Yee WM and Worley PF: Rheb interacts with Raf-1 kinase and may function to integrate growth factor- and protein kinase A-dependent signals. Mol Cell Biol 17: 921-933, 1997.

46. Richards JS: New signaling pathways for hormones and cyclic adenosine 3',5'-monophosphate action in endocrine cells. Mol Endocrinol 15: 209-218, 2001. 